British Journal of Psychiatry (1995), 167, 112-119

\title{
Correspondence
}

Contents: Economics of treatment of depression/ The costs of psychotropic medication/Self-measure of neuroleptic side-effects/Dystonia and neuroleptic medication/Charles Bonnet syndrome/The cultural context of hallucinations/Mental health tribunals/ ECT seizure threshold/The Chinese classification of mental disorders/Rhabdomyolysis due to mania.

\section{Economics of treatment of depression}

SIR: I was surprised to read in the economic analysis of Jönsson \& Bebbington (1994) that the expected costs of treatment with imipramine and paroxetine are roughly equal.

Checking in the British National Formulary $(B N F, 1993)$ the costs of the two drugs are as follows: 30 days of imipramine $150 \mathrm{mg}$ is $£ 0.99$ $(180 \times 25 \mathrm{mg}$ tablets at $£ 0.11$ per 20 tablets), and 30 days of paroxetine $30 \mathrm{mg}$ at $£ 50.85$. In other words, paroxetine is about 50 times more expensive than imipramine.

Jönsson \& Bebbington tell us that paroxetine is only 5 or 6 time more expensive. However, although their cost of $£ 1.13$ per day for paroxetine equates with a daily dose of $20 \mathrm{mg}$, their cost of f0.20 per day for imipramine is equivalent to a daily dose of over $900 \mathrm{mg}(B N F, 1993)$.

This almost ten-fold exaggeration in one of the two fundamental costs in the analysis means that the finding of the study is no more plausible after close scrutiny than it was at first glance.

British National Formulary (1993) No. 26, September 1993. Jonsson, B. \& BebBngton, P. E. (1994) What price depression? The cost of depression and the cost-effectiveness of pharmacological treatment. British Journal of Psychiatry, 164, 665-673.

University of Leeds

D.W. OWENS

Leeds LS2 9LT

Authors' REPLY: We thank Dr Owens for his interest in our article on the cost effectiveness of antidepressant treatment (BJP, May 1994, 164, 665-673). Thus, the costs for imipramine in our calculation were based on the price for the branded product Tofranil. The cost of $25 \mathrm{mg}$ tablets in March 1990 was 63 pence for twenty. The cost of 6 tablets daily works out at 19 pence per day. This was the value used in our model.

B. JÖNSSON

Stockholm School of Economics Sweden

Institute of Psychiatry

P.E. Bebbington London SE5 8AF

SIR: I noted with some amusement that the Freemantle et al (1995) critique of the Jönsson \& Bebbington economic analysis of antidepressants devoted two out of its six paragraphs to a discussion of the funding arrangements and commercial associations of the authors. I also have been in receipt of this kind of treatment by Freemantle and his team in York. On that occasion the British Medical Journal had quite rightly required me and my co-author to state any vested interest, which we were pleased to do. I noted then, and I note once more, that Freemantle and colleagues have neglected to declare that their unit is heavily funded by Her Majesty's Treasury via the Department of Health. No doubt he is as keen to satisfy his powerful sponsor as are his opponents in the "great antidepressant debate". There is no such thing as unbiased research and Freemantle should in future restrict his comments to scientific analysis. If that does not suffice it surely indicates that he has lost his case.

Freemantle, N., House, A., Mason, J., et al (1995) Economics of treatment of depression (letter). British Journal of Psychiatry, 166, 397.

Royal South Hants Hospital

C. THOMPSON

Southampton SO14 OYG

The costs of psychotropic medication

SIR: Recent correspondence on the cost of SSRIs and the relevance of economic models to psychiatric practice (Freemantle et al, 1995; Jönsson \& Bebbington, 1995), as well as previous articles and correspondence on the costs and relevance of models of the cost of clozapine (Healy, 1993a, b; Bosanquet \& Zajdler, 1993) have prompted us to 